\title{
Use of iliac screw associated with more correction of lumbar lordosis than S2-alar- iliac screw for adult spinal deformity
}

Qiang Luo ${ }^{1,2}$, Yong-Chan Kim ${ }^{1 *}$, Ki-Tack Kim ${ }^{1}$ Kee-Yong Ha' ${ }^{1}$ Joonghyun Ahn ${ }^{1}$, Sung-Min Kim ${ }^{1}$ and Min-Gyu Kim ${ }^{1}$

\begin{abstract}
Background: To date, there is a paucity of reports clarifying the change of spinopelvic parameters in patients with adult spinal deformity (ASD) who underwent long segment spinal fusion using iliac screw (IS) and S2-alar-iliac screw (S2Al) fixation.

Methods: A retrospective review of consecutive patients who underwent deformity correction surgery for ASD between 2013 and 2017 was performed. Patients were divided into two groups based on whether IS or S2AI fixation was performed. All radiographic parameters were measured preoperatively, immediately postoperatively, and the last follow-up. Demographics, intraoperative and clinical data were analyzed between the two groups. Additionally, the cohort was subdivided according to the postoperative change in pelvic incidence (PI): subgroup (C) was defined as change in $\mathrm{PI} \geq 5^{\circ}$ and subgroup (NC) with change $<5^{\circ}$. In subgroup analyses, the 2 different types of postoperative change of PI were directly compared.
\end{abstract}

Results: A total of 142 patients met inclusion criteria: 111 who received IS and 31 received S2Al fixation. The IS group $\left(65.6 \pm 26^{\circ}, 39.8 \pm 13.8^{\circ}\right)$ showed a significantly higher change in lumbar lordosis (LL) and upper lumbar lordosis (ULL) than the S2AI group $\left(54.4 \pm 17.9^{\circ}, 30.3 \pm 9.9^{\circ}\right)(p<0.05)$. In subgroup (C), PI significantly increased from $53^{\circ}$ preoperatively to $59^{\circ}$ postoperatively at least $50 \%$ of IS cohort, with a mean change of $5.8^{\circ}(p<0.05)$. The clinical outcomes at the last follow-up were significantly better in IS group than in S2Al group in terms of VAS scores for back and leg. The occurrence of sacroiliac joint pain and pelvic screw fracture were significantly greater in S2Al group than in IS group (25.8\% vs $9 \%, p<0.05)$ and $(16.1 \%$ vs $3.6 \%, p<0.05)$.

Conclusions: Compared with the S2AI technique, the IS technique usable larger cantilever force demonstrated more correction of lumbar lordosis, and possible increase in pelvic incidence. Further study is warranted to clarify the clinical impaction of these results.

Keywords: Adult spinal deformity, lliac screw, s2-alar-iliac screw, Spinopelvic parameters

\footnotetext{
* Correspondence: yckimspine@gmail.com

'Department of Orthopaedic Surgery, College of Medicine, Kyung Hee

University Hospital at Gangdong, Kyung Hee University, 892 Dongnam-ro,

Gangdong-gu, Seoul 05278, South Korea

Full list of author information is available at the end of the article
}

C C The Author(s). 2021 Open Access This article is licensed under a Creative Commons Attribution 4.0 International License, which permits use, sharing, adaptation, distribution and reproduction in any medium or format, as long as you give appropriate credit to the original author(s) and the source, provide a link to the Creative Commons licence, and indicate if changes were made. The images or other third party material in this article are included in the article's Creative Commons. licence, unless indicated otherwise in a credit line to the material. If material is not included in the article's Creative Commons licence and your intended use is not permitted by statutory regulation or exceeds the permitted use, you will need to obtain permission directly from the copyright holder. To view a copy of this licence, visit http://creativecommons.org/licenses/by/4.0/ The Creative Commons Public Domain Dedication waiver (http://creativecommons.org/publicdomain/zero/1.0/) applies to the data made available in this article, unless otherwise stated in a credit line to the data. 


\section{Background}

Spinopelvic fixation (SPF) is becoming an increasingly important avenue for degenerative conditions as the aging population grows. This instrumentation technique can also be applied in high-grade spondylolisthesis, trauma, tumors or infection. However, achieving solid fixation in lumbosacral junction continues to be a challenge for spine surgeons because of the tremendous biomechanical forces demand across the junctional area, complex regional anatomy, and a high pseudarthrosis rate, especially in patients with adult spinal deformity (ASD) [1-5]. With the emergence of advanced spinal instrumentation, multiple options have been described for additional SPF over the past decades. Currently, iliac screw (IS) and S2-alar-iliac (S2AI) screw fixations are the most popular method of SPF in clinical practice.

The IS had a long-established history of improving stability, with comparative advantages of greater diameter and length bolts could be used, higher pullout strength, and easier application [6]. However, there are some disadvantages regarding the IS, including the need for lateral connector, more extensive tissue dissection, prominent hardware, and wound dehiscence etc. [3, 7 , 8]. Tsuchiya et al. [9] reported that up to $34 \%$ ASD patients treated via IS technique necessitating reoperations due to prominence.

In response to above drawbacks, the S2AI has recently become an increasingly popular technique as an alternative method of SPF, which was initially described by Dr. Sponseller [10]. This technique prevented hardware prominence owing to its deeper and more medial entry point compared to IS [7]. Additional, current literature reported the S2AI had several potential advantages over IS with lower rates of reoperation, wound dehiscence, and implant failure [4, 11-13]. However, there are limited data regarding comparative data between these techniques. To date, few studies exist specifically focused on the radiographic change of spinopelvic parameters after SPF utilizing IS and S2AI techniques. Therefore, the aim of this study was to compare the radiographic change of sagittal spinopelvic parameters between these two techniques for the treatment of ASD, and assess the complication rate of our substantial case series.

\section{Methods}

After institutional review board approval, we performed a retrospective review of consecutive patients who underwent long-segment ( $\geq 6$ levels) spinal fusion and pelvic fixation using IS or S2AI technique at a single institution between 2013 and 2017. The indications for surgery included frequent recurrent low-back and/or leg pain, neurological deficits, severe disability and/or progressive deformity that failed to better with conservative treatment for more than 6 months. We included ASD patients with age $\geq 60$ years and at least one of the following: C7 sagittal vertical axis (SVA) >50 mm, pelvic tilt $(\mathrm{PT})>25^{\circ}$, pelvic incidence $(\mathrm{PI})$ - lumbar lordosis (LL) $>10^{\circ}$. Patients with a history of neuromuscular diseases, malignancy, infection, and postoperative follow-up less than 24 months were excluded. Furthermore, patients were also excluded from this study if they had ankylosing spondylitis, Parkinson's disease, or incomplete radiographic and clinical records. Eligible patients were divided into 2 groups according to the surgical method: IS group (iliac screw fixation) and S2AI group (S2-alariliac screw fixation).

The clinical data for this current cohort were obtained from the electronic medical records and operative database of our institution. Standard demographic data (e.g., age, gender, primary diagnosis, medical comorbidities, and American Society of Anesthesiologists [ASA] [14] classification) were extracted. Surgical parameters included the operated levels, estimated blood loss (EBL), surgical duration, use of an osteotomy, and length of stay (LOS). The major complications requiring revision included proximal junctional kyphosis (PJK), pseudarthrosis, deep infection, sacroiliac joint (SIJ) pain, or other implant-related complications (pelvic screw loosening, fracture, and wound dehiscence etc.) were compared. Clinical results were evaluated using the Visual Analog Scale (VAS) [15] of back and leg pain and Oswestry Disability Index (ODI) [16] at preoperative and 3 months postoperative, and the last follow-up.

\section{Surgical procedures}

The IS procedure was performed base on the technique described previously $[1,6,17-19]$. With patients in the prone position, suprafascial dissection was performed via a midline incision. Routine exposure of the spinous process, lamina, facet joints, and transverse process at the index levels. The bilateral posterior superior iliac spine (PSIS) were then identified. Adequate subperiosteal dissection was performed and splitted fascia longitudinally over the PSIS midline, then stripped to the sides for fascial integrity. The ideal entry point of IS was about $10 \mathrm{~mm}$ between the posterior edge of the iliac crest and posterior sacrum. An osteotome was used to remove a small tri- cortical wedge around this point. A straight probe was gently and cautiously inserted into the cancellous channel of ilium, avoiding penetration of inner and outer cortex. Next, the trajectory was tapped with a balltip probe to verify the integrity of cortical bone. Then the screw was deeply inserted toward PSIS until its head was flush with the cortex of the ilium to lower the risk of prominence. Finally, the screw was attached to the rod underneath S1 pedicle screw using a lateral connector (Fig. 1). 


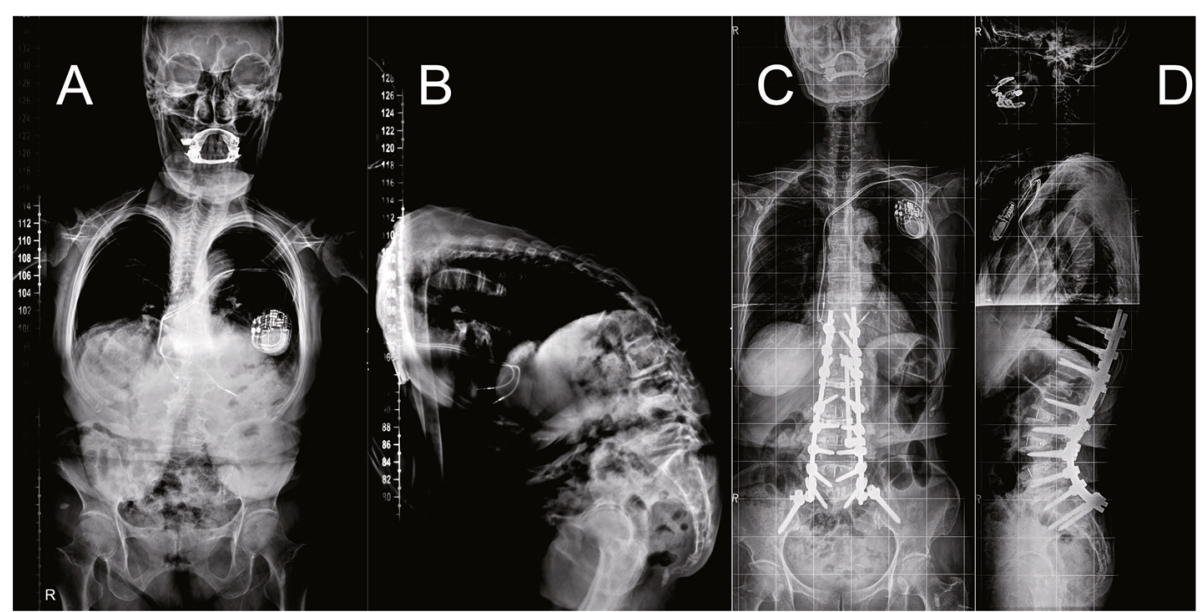

Fig. 1 A 78-year-old female patient from IS group. The SVA, PT, and LL were $337.7 \mathrm{~mm}, 40.4^{\circ}$ and $36.4^{\circ}$ preoperatively (A and $\left.\mathbf{B}\right)$ and changed to $12 \mathrm{~mm}, 18.5^{\circ}$, and $-49.9^{\circ}$ after surgery (C and $\left.\mathbf{D}\right)$. IS indicates iliac screw

The procedure of S2AI fixation was performed using a free hand technique described previously [7, 20-24]. A routine posterior exposure was performed similar as IS. S2AI technique has a sacral ala entry point locating distal to the S1 foramen with the angulation of trajectory approximately $30-45^{\circ}$ laterally and $25-40^{\circ}$ distally, aiming toward the greater trochanter of the femur. Using fluoroscopy to ensure position cephalad to the greater sciatic notch and tap drilling until the SIJ, then reverse drilling until the iliac cortex was reached. Finally, the screw was inserted until its head placed in-line with S1 pedicle screw head (Fig. 2).

We commonly used the pelvic screw with a diameter of $8.5 \mathrm{~mm}$ and a length of $70 \mathrm{~mm}$. All cases were performed as 2-stage anteroposterior fusion with an interval of 1 week by the two senior authors (KKT and $\mathrm{KYC}$ ) as a team with $>20$ years of experience in ASD. The IS and S2AI techniques were equally selected from May 2013 to December 2015, but IS was preferentially utilized from January 2016, since we

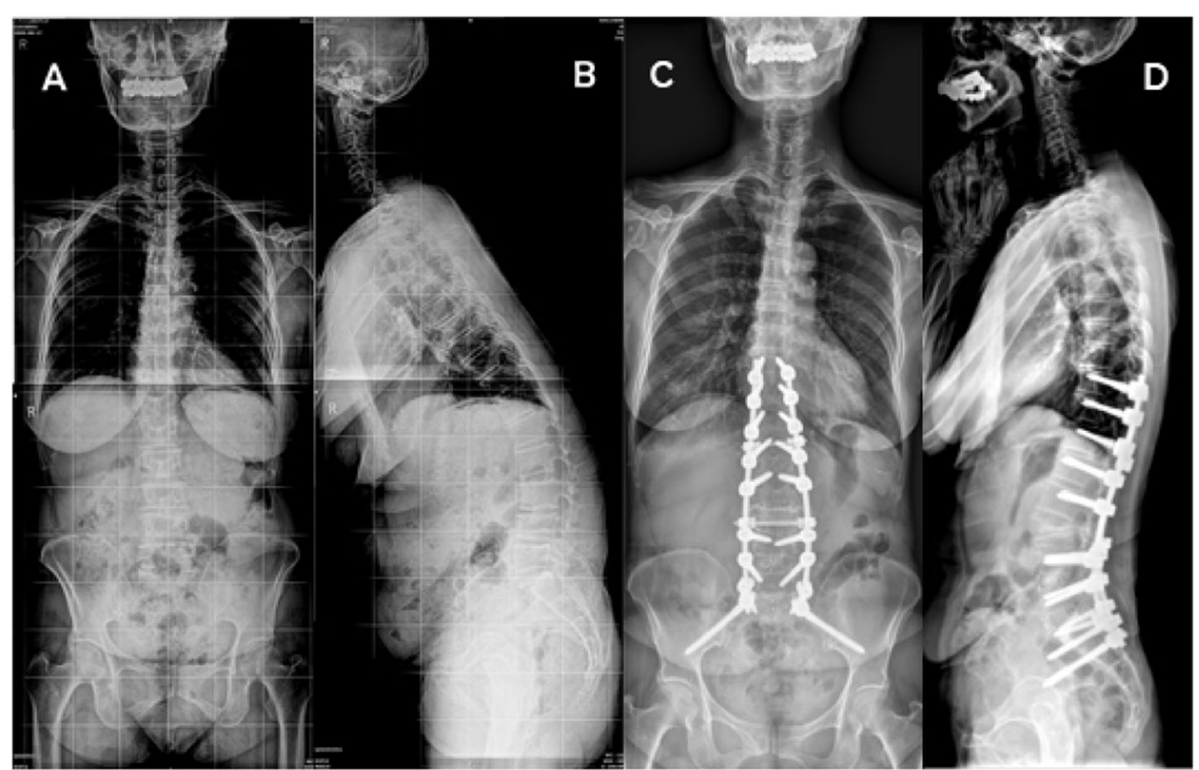

Fig. 2 A 72-year-old female patient from S2AI group. The SVA, PT, and LL were $200.1 \mathrm{~mm}, 27.6^{\circ}$ and $2.5^{\circ}$ preoperatively (A and B) and changed to $9.2 \mathrm{~mm}, 17.6^{\circ}$, and -58.5 after surgery (C and $\left.\mathbf{D}\right)$. S2Al indicates S2-Alar-iliac 
were aware of the advantage of IS technique for getting cantilever force.

\section{Radiological evaluation}

All radiological analysis was performed on lateral radiographs of whole spine (36-in.) obtained preoperatively, postoperatively (first erect) and at the last follow-up according to an established positioning protocol [25]. Spinopelvic parameters included in this analysis were SVA, PT, PI, LL (L1-S1), TK (thoracic kyphosis: T5-12), ULL (upper lumbar lordosis: L1-4), and LLL (lower lumbar lordosis: L4-S1) [26]. Kyphosis was indicated by a $(+)$ value whereas lordosis was indicated by a $(-)$ value. Change of parameter was calculated by subtracting the preoperative value from the postoperative value. All the parameters were measured by two surgeons who did not participate in the operation and the mean value were adopted.

Additionally, we defined PJK was considered present when proximal junctional angle was $>10^{\circ}$ and at least $10^{\circ}$ greater than the preoperative measurement, which was a severe complication after deformity surgery with radiographic evidence of acute PJK deformity and mechanical failure at the upper instrumented vertebra (UIV) [27]. Fusion was confirmed by the presence of bridging bone connecting the adjacent vertebral bodies either through the implants or around the implants or $<3 \mathrm{~mm}$ of translation on flexion or extension radiographs [2830]. Screw loosening was defined as a radiolucent area $\geq$ $2 \mathrm{~mm}$ surrounding the screw on radiographic images, also known as the "double halo sign [31, 32]". SIJ pain was defined as unilateral buttock pain meeting the following criteria within 3 months of surgery: SIJ score $>4$ [33]; no implant misplacement and prominence; and no surgical site dehiscence and infection.

\section{Statistical analysis}

Results were expressed as mean \pm SD. We used the Student's t-test for continuous variables, and the Chi-square test used for categorical variables. All statistical analyses were performed using SPSS 21.0 software (SPSS Inc., Chicago, IL, USA) with $p$ values of $<0.05$ considered to be statistically significant.

\section{Results}

\section{Patient characteristics and perioperative data}

In total, 142 patients with a mean follow-up duration of 32.3 months were included in the study and analysis: 111 received IS technique and 31 received S2AI technique. The mean age was 67.3 years and the BMI $28.3 \mathrm{~kg} / \mathrm{m}^{2}$, $82.4 \%$ of patients were female. With regard to surgical data, the mean number of levels fused ( 8.8 vs $8.7, p=$ 0.084 ) between the 2 groups were not significantly different. The mean estimated blood loss (EBL) were $2421 \mathrm{ml}$ and $2368 \mathrm{ml}$ in IS and S2AI groups, respectively $(p>0.05)$. Mean surgical duration in IS group was slightly more than in S2AI group ( $388.2 \pm 99.1 \mathrm{~min}$ vs $377.6 \pm 102.1 \mathrm{~min}, p=$ 0.602 ). As shown in Table 1, the comparative analyses revealed no significant intergroup differences in age, sex,

Table 1 Baseline demographics and surgical data between the IS and S2Al groups

\begin{tabular}{|c|c|c|c|}
\hline & IS & S2AI & $p$ \\
\hline No. of patients & 111 & 31 & \\
\hline Age, (yrs) & $67.9 \pm 16.7$ & $65.2 \pm 15.8$ & 0.422 \\
\hline Female sex, n (\%) & $92(82.8)$ & 25 (80.6) & 0.772 \\
\hline BMI, $\left(\mathrm{kg} / \mathrm{m}^{2}\right)$ & $28.5 \pm 8.7$ & $27.6 \pm 8.2$ & 0.607 \\
\hline Follow-up, (mos) & $32.8 \pm 8.0$ & $30.7 \pm 6.2$ & 0.179 \\
\hline Smoking, n (\%) & $12(10.8)$ & $5(16.1)$ & 0.530 \\
\hline Diabetes, n (\%) & $32(28.8)$ & $9(29.0)$ & 0.982 \\
\hline Osteoporosis, n (\%) & $53(47.7)$ & $13(41.9)$ & 0.566 \\
\hline Hypertension, n (\%) & $11(9.9)$ & $5(16.1)$ & 0.518 \\
\hline Primary diagnosis, n (\%) & & & 0.891 \\
\hline Degenerative & $72(64.95)$ & $19(61.3)$ & \\
\hline Idiopathic & $14(12.6)$ & $4(12.9)$ & \\
\hline Congenital & $7(6.3)$ & $3(9.7)$ & \\
\hline Post-traumatic & $18(16.2)$ & $5(16.1)$ & \\
\hline ASA class, n (\%) & & & 0.379 \\
\hline I & $14(12.6)$ & $7(22.6)$ & \\
\hline$\|$ & 79 (71.2) & $19(61.3)$ & \\
\hline III & $18(16.2)$ & $5(16.1)$ & \\
\hline No. of levels fused & $8.82 \pm 3.7$ & $8.65 \pm 7.6$ & 0.084 \\
\hline UIV level, n (\%) & & & 0.802 \\
\hline Above T10 & $9(8.1)$ & $2(6.5)$ & \\
\hline $\mathrm{T} 10$ & $89(80.2)$ & $24(77.4)$ & \\
\hline Below T10 & $13(11.7)$ & $5(16.1)$ & \\
\hline \multicolumn{4}{|l|}{ Interbody fusion level } \\
\hline $\mathrm{L} 1 / 2$ & $11(9.9)$ & $2(6.5)$ & 0.734 \\
\hline$L 2 / 3$ & $101(90.9)$ & $27(87.1)$ & 0.506 \\
\hline $\mathrm{L} 3 / 4$ & $109(98.2)$ & $29(93.5)$ & 0.208 \\
\hline$\llcorner 4 / 5$ & $110(99.1)$ & $30(96.8)$ & 0.390 \\
\hline$L 5 / S 1$ & $109(98.2)$ & $30(96.8)$ & 0.525 \\
\hline \multicolumn{4}{|l|}{ PSO level, n (\%) } \\
\hline L2 & $5(4.5)$ & $2(6.5)$ & 0.647 \\
\hline L3 & $8(7.2)$ & $3(9.7)$ & 0.705 \\
\hline$\llcorner 4$ & $2(1.8)$ & $1(3.2)$ & 0.525 \\
\hline Surgical duration (mins) & $388.2 \pm 99.1$ & $377.6 \pm 102.1$ & 0.602 \\
\hline Blood loss (ml) & $2421.2 \pm 255.1$ & $2368.3 \pm 354.1$ & 0.353 \\
\hline Length of stay (days) & $20.6 \pm 5.7$ & $19.1 \pm 6.8$ & 0.217 \\
\hline
\end{tabular}

IS Iliac screw, S2AI S2-alar-iliac, BMI Body mass index, ASA American Society of Anesthesiologists, UIV Upper instrumented vertebra, PSO Pedicle subtraction osteotomies 
primary diagnosis, comorbidities, LOS, and other perioperative data.

\section{Radiographic outcomes}

Changes in the radiological spinopelvic parameters of all patients are summarized in Table 2. At enrollment, there

Table 2 Comparison of spinopelvic parameters between the IS and S2Al groups

\begin{tabular}{|c|c|c|c|}
\hline Parameter & IS & S2AI & $p$ \\
\hline \multicolumn{4}{|l|}{ SVA (mm) } \\
\hline Preop & $155.5 \pm 55.3$ & $139.3 \pm 41.9$ & 0.133 \\
\hline Postop & $20.9 \pm 33.5$ & $32.2 \pm 30.4$ & 0.093 \\
\hline Last follow-up & $46.8 \pm 51.0$ & $67.2 \pm 69.0$ & 0.07 \\
\hline Change & $-134.6 \pm 49.3$ & $-107.1 \pm 55.3$ & 0.005 \\
\hline \multicolumn{4}{|l|}{ TK $\left(^{\circ}\right)$} \\
\hline Preop & $7.1 \pm 12.2$ & $8.1 \pm 12.0$ & 0.686 \\
\hline Postop & $26.9 \pm 8.1$ & $24.1 \pm 10.9$ & 0.119 \\
\hline Last follow-up & $29.6 \pm 9.9$ & $27.0 \pm 11.2$ & 0.211 \\
\hline Change & $19.8 \pm 10.3$ & $16.0 \pm 12.0$ & 0.082 \\
\hline \multicolumn{4}{|l|}{ PT $\left(^{\circ}\right)$} \\
\hline Preop & $37.1 \pm 8.7$ & $38.3 \pm 10.1$ & 0.514 \\
\hline Postop & $17.4 \pm 7.2$ & $26.2 \pm 8.5$ & $<0.001$ \\
\hline Last follow-up & $20.3 \pm 7.6$ & $27.7 \pm 8.9$ & $<0.001$ \\
\hline Change & $-19.7 \pm 11.9$ & $-12.1 \pm 8.9$ & $<0.001$ \\
\hline \multicolumn{4}{|l|}{$\mathrm{PI}\left({ }^{\circ}\right)$} \\
\hline Preop & $54.8 \pm 9.5$ & $56.8 \pm 11.4$ & 0.324 \\
\hline Postop & $56.1 \pm 8.4$ & $56.2 \pm 10.9$ & 0.956 \\
\hline Last follow-up & $55.9 \pm 10.6$ & $56.6 \pm 9.7$ & 0.741 \\
\hline Change & $1.3 \pm 4.3$ & $-0.6 \pm 7.3$ & 0.069 \\
\hline \multicolumn{4}{|l|}{ LL $\left({ }^{\circ}\right)$} \\
\hline Preop & $11.4 \pm 23.9$ & $12.1 \pm 5.3$ & 0.872 \\
\hline Postop & $-54.2 \pm 10.0$ & $-42.3 \pm 7.8$ & $<0.001$ \\
\hline Last follow-up & $-51.7 \pm 13.8$ & $-39.5 \pm 8.1$ & $<0.001$ \\
\hline Change & $-65.6 \pm 26.0$ & $-54.4 \pm 17.9$ & 0.028 \\
\hline \multicolumn{4}{|l|}{ ULL $\left(^{\circ}\right)$} \\
\hline Preop & $7.1 \pm 8.4$ & $6.6 \pm 11.9$ & 0.791 \\
\hline Postop & $-32.7 \pm 9.7$ & $-23.7 \pm 9.3$ & $<0.001$ \\
\hline Last follow-up & $-29.9 \pm 8.6$ & $-21.3 \pm 10.4$ & $<0.001$ \\
\hline Change & $-39.8 \pm 13.8$ & $-30.3 \pm 9.9$ & $<0.001$ \\
\hline \multicolumn{4}{|l|}{$\operatorname{LLL}\left({ }^{\circ}\right)$} \\
\hline Preop & $4.3 \pm 7.1$ & $5.5 \pm 9.9$ & 0.449 \\
\hline Postop & $-21.5 \pm 10.4$ & $-18.6 \pm 10.8$ & 0.176 \\
\hline Last follow-up & $-18.8 \pm 9.7$ & $-18.2 \pm 9.4$ & 0.760 \\
\hline Change & $-25.8 \pm 19.9$ & $-24.1 \pm 13.5$ & 0.655 \\
\hline
\end{tabular}

IS lliac screw, S2AI S2-alar-iliac, SVA Sagittal vertical axis, TK Thoracic kyphosis, PT Pelvic tilt, PI Pelvic incidence, LL Lumbar lordosis, ULL Upper lumbar lordosis, LLL Lower lumbar lordosis, Preop Preoperative, Postop Postoperative; Change, postoperative - preoperative were no differences in any preoperative parameters between the two groups. Except PI, the improvement achieved after surgery were maintained in all parameters, and subsequently maintained at the last follow-up. LL significantly changed from $11.4 \pm 23.9^{\circ}$ preoperatively to $-54.2 \pm 10^{\circ}$ postoperatively in IS group, ULL was 7.1 \pm $8.4^{\circ}$ preoperatively and $-32.7 \pm 9.7^{\circ}$ after surgery. LL significantly changed from $12.1 \pm 5.3^{\circ}$ preoperatively to $42.3 \pm 7.8^{\circ}$ postoperatively in S2AI group, ULL was $6.6 \pm$ $11.9^{\circ}$ preoperatively and $-23.7 \pm 9.3^{\circ}$ after surgery. In IS group, the mean preoperative SVA of $155.5 \mathrm{~mm}$ decreased to $20.9 \mathrm{~mm}$ after surgery and was $46.8 \mathrm{~mm}$ at the last follow-up. In S2AI group, the mean preoperative SVA of $139.3 \mathrm{~mm}$ decreased to $32.2 \mathrm{~mm}$ after surgery and was $67.2 \mathrm{~mm}$ at the last follow-up. The mean PT was $37.1^{\circ}$ preoperatively, improved to $17.4^{\circ}$ postoperatively, and changed to $20.3^{\circ}$ at the last follow-up in IS group. It was $38.3^{\circ}$ before surgery, corrected to $26.2^{\circ}$ after surgery, and changed to $27.7^{\circ}$ at the last follow-up in S2AI group.

Intergroup analysis showed that, IS group had significantly greater magnitudes of improvement from preoperative to postoperative in SVA, PT, LL and ULL. Preoperative values for SVA decreased $65.6 \pm 26^{\circ}$ in IS group vs $39.8 \pm 13.8^{\circ}$ in S2AI group $(p<0.05)$. The IS group also experienced greater reduction of PT (IS: $19.7^{\circ}$ vs S2AI: $\left.-12.1^{\circ} ; p<0.01\right)$. IS group had larger increases in LL (IS: $66^{\circ}$ vs S2AI: $54^{\circ} ; p=0.028$ ) and ULL (IS: $40^{\circ}$ vs S2AI: $30^{\circ} ; \mathrm{p}<0.01$ ) than S2AI group.

For the further analysis, the cohort was subdivided based on the postoperative change in PI (Table 3): a change $\geq 5^{\circ}$ subgroup (C) $(\mathrm{IS}=64, \mathrm{~S} 2 \mathrm{AI}=4)$ and a change $<5^{\circ}$ subgroup $(\mathrm{NC})(\mathrm{IS}=47, \mathrm{~S} 2 \mathrm{AI}=27)$. In subgroup (C), PI significantly increased from $53.3^{\circ}$ preoperatively to $59.1^{\circ}$ postoperatively at least $50 \%$ of IS cohort, with a mean change of $5.8^{\circ}(p=0.032)$.

\section{Clinical outcomes and complications}

The preoperative back and leg VAS scores and the ODI scores were similar between two groups (Table 4). Although the scores for back and leg, and the ODI scores were greater in IS group than in S2AI group at 3 months postoperatively, the differences between the two groups were not statistically significant. At the last follow-up, the back and leg VAS scores were significantly lower in IS group than in S2AI group (back VAS score: $3.39 \pm$ 1.26 vs $3.92 \pm 1.36, p=0.044$; leg VAS score: $3.52 \pm 1.03$ vs $3.95 \pm 1.12, p=0.046)$. The ODI showed no significant difference between two groups at the last follow-up.

Table 5 described postoperative complications. The occurrence of SIJ pain was significantly higher in S2AI group than in IS group $(p=0.029)$. The S2AI group had significantly more pelvic screw fracture than IS group (S2AI $16.1 \% \%$ vs IS $3.6 \% ; p=0.035$ ). There were four 
Table 3 Stratification based on the postoperative change in PI between the IS and S2AI groups

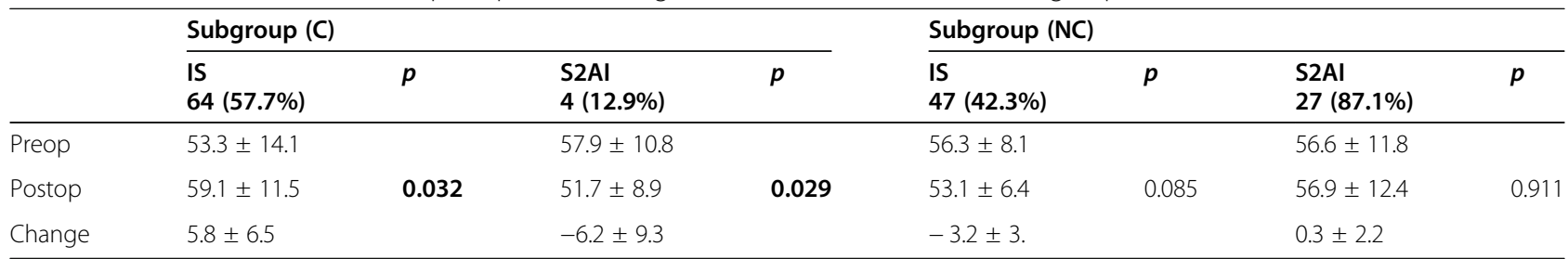

IS Iliac screw, S2AI S2-alar-iliac screw, PI Pelvic incidence, Preop Preoperative, Postop Postoperative; change, postoperative - preoperative; Subgroup (C), postoperative change in $\mathrm{PI} \geq 5^{\circ}$; Subgroup (NC), postoperative change in $\mathrm{PI}<5^{\circ}$. The $p$ value represents the comparison between the preoperative value and postoperative value

postoperative infections in IS group compared with two in S2AI group $(p>0.05)$. Rates of PJK, pseudarthrosis, wound dehiscence, or screw loosening were similar between two groups.

\section{Discussion}

The present study demonstrates three major findings:

(1) Historically, both spinopelvic fusion techniques reported in this paper have demonstrated similar effects in terms of stiffness and stability [24, 34]. However, when the differences from baseline to immediately postoperative were compared in the current study, the IS group had significantly greater amounts of correction in LL and ULL. Our study is the first to report that the IS technique could get more correction of lumbar lordosis compared to the S2AI technique used to ASD. There may be two reasons for this: one is that the S2AI technique insertion point is reported to be $15 \mathrm{~mm}$ deeper than that in the IS technique [35]. Furthermore, we could observe the curved rod application in the distal area in the coronal plane of S2AI group, which showed worse resistance against distal implant pullout and

Table 4 Comparison of VAS and ODI between the IS and S2AI groups

\begin{tabular}{llll}
\hline Clinical Outcomes & IS & S2AI & p \\
\hline VAS (back) & & & \\
Preop & $7.97 \pm 2.81$ & $7.55 \pm 3.12$ & 0.474 \\
3 mos postop & $3.37 \pm 1.41$ & $3.19 \pm 1.14$ & 0.515 \\
Last follow-up & $3.39 \pm 1.2$ & $3.92 \pm 1.36$ & $\mathbf{0 . 0 4 4}$ \\
VAS (leg) & & & \\
Preop & $7.12 \pm 1.93$ & $7.31 \pm 2.52$ & 0.652 \\
3 mos postop & $3.41 \pm 2.12$ & $3.32 \pm 1.84$ & 0.830 \\
Last follow-up & $3.52 \pm 1.03$ & $3.95 \pm 1.12$ & $\mathbf{0 . 0 4 6}$ \\
ODI & & & \\
Preop & $49.54 \pm 21.25$ & $48.24 \pm 19.67$ & 0.760 \\
3 mos postop & $18.31 \pm 2.96$ & $17.96 \pm 1.43$ & 0.525 \\
Last follow-up & $21.64 \pm 7.63$ & $24.37 \pm 5.94$ & 0.068 \\
\hline
\end{tabular}

IS lliac screw, S2AI S2-alar-iliac screw, Preop Preoperative, Postop Postoperative, VAS Visual Analog Scale, ODI Oswestry Disability Index decreased strain between the screw head and shaft. The S2AI technique is enhanced with iliac buttressing, but the location of the rods is probably too medial to correct more LL. These differences can be further appreciated in Fig. 3 (a graphical rendering of the IS vs S2AI fixation).

(2) PI is a unique anatomical parameter and often considered a constant value after maturity [36]. Most surgeons suggest PI is the key parameter needed to estimate the ideal LL to be restored after spine surgery. However, the current literature [37-39] questions this characteristic of constant PI, claiming that PI may change under certain circumstances. In addition, PI could be changed by motion of the SIJ if it is influenced by various forces due to joint motion or position during supine, sitting, or locomotion behaviors. Thus, the laxity of the SIJ serves as one basis for the change in PI. Nutation increases PI and counternutation decreases PI due to motion at the SIJ [40]. The changes in PI occur in patients who undergo lumbosacral fixation using the IS technique while the changes associated with the S2AI technique have not been well established. Five degrees was determined as a cutoff threshold because deviation may occur owing to varied postures during imaging and measurement and the magnitude of SIJ movement in adulthood has been reported to be $1-4^{\circ}$ of rotation [ $41-$ 43]. Our hypothesis is that mobility in the SIJ could determine the difference in the final shape of the pelvis after surgery, and different surgical techniques would lead to different outcomes in this parameter. The SIJ is

Table 5 Comparison of postoperative complications and reoperations between the IS and S2AI groups

\begin{tabular}{llll}
\hline Variable, $\boldsymbol{n}(\boldsymbol{\%})$ & IS $(\boldsymbol{n}=\mathbf{1 1 1})$ & S2A $(\boldsymbol{n}=\mathbf{3 1 )}$ & $\boldsymbol{p}$ \\
\hline SIJ pain & $10(9)$ & $8(25.8)$ & $\mathbf{0 . 0 2 9}$ \\
Pelvic screw loosening & $18(16.2)$ & $4(12.9)$ & 0.865 \\
Pelvic screw fracture & $4(3.6)$ & $5(16.1)$ & $\mathbf{0 . 0 3 5}$ \\
Pseudarthrosis & $3(2.7)$ & $2(6.5)$ & 0.653 \\
Infection (deep) & $4(3.6)$ & $2(6.5)$ & 0.848 \\
Wound dehiscence & $1(0.9)$ & $1(3.2)$ & 0.913 \\
Proximal junctional kyphosis & $8(7.2)$ & $4(12.9)$ & 0.520 \\
\hline
\end{tabular}

IS lliac screw, S2AI S2-alar-iliac screw, SIJ Sacroiliac joint 


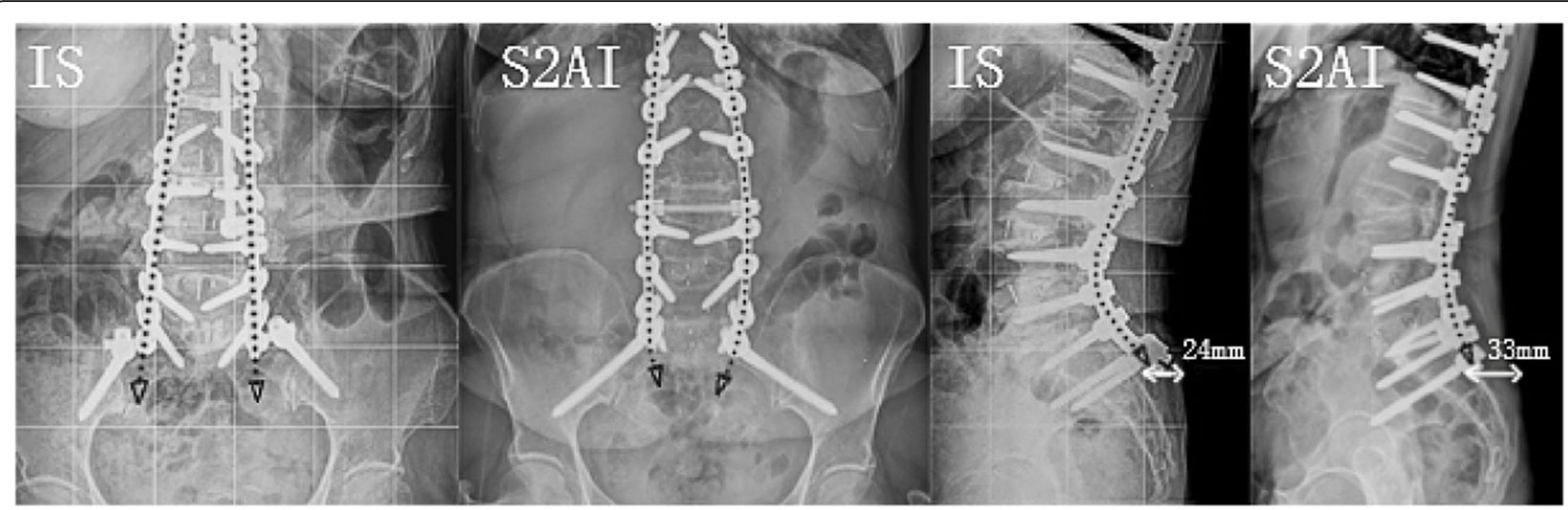

Fig. 3 Cantilever force in coronal plane anchoring at ilium between IS and S2AI technique. Rod application in S2Al fixation: curved rod in coronal plane, Low anchoring level in sagittal plane. IS indicates iliac screw; S2Al, S2-alar-iliac screw

six times more resistant to lateral forces than the lumbar spine, and approximately one-half as resistant to axial direction and rotation forces [44]. Hence, stress on the SIJ could increase after spinal fusion that could accelerate degenerative changes, resulting in an increase in motion, particularly that which occurs more frequently after SPF $[45,46]$. Specifically, we hypothesize that forced extension of the hips and lumbar spine on the operating table could cause anterior rotation of the sacrum into the pelvis, resulting in an intraoperative increase in PI. If the IS technique was used, this change would be fixed, with a consequent postoperative increase in the observed PI.

Pelvic retroversion generates a reaction force on the SIJ in patients with sagittal malalignment, destabilizing the joint, particularly if combined with degeneration. During surgery, the S2AI screws were placed through the SIJ, reconstructing the morphology of the pelvis. As a consequence, we observed a dramatic decrease in PI. The discrepancy between our postoperative change in PI and that reported by other studies [47] indicates that the potential mechanism may be related to multiple factors. According to cadaveric data [21], over half of S2AI surgeries violated the SIJ, which could potentially affect PI. In addition, postoperative changes in PI are a complicated biological phenomenon in vivo, which are challenging to test in cadavers or biomechanically. However, this result provided some insight into how spinal alignment may be affected by instrumentation and how it is translated into clinical outcomes, though further prospective study is warranted.

(3) The S2AI Group showed a significantly higher rate of pelvic screw breakage than the IS Group. There may be two reasons for this: one is that the acute angle that develops between the screw head and shaft of the screw, may be more prone to failure in the extremes of headshaft angulation. The second reason may be that the distribution of stresses into two connections with the IS as opposed to a single one with the S2AI are different. Further research is needed to develop a better understanding of these particular types of failure.

In addition, hardware prominence and subsequent pain in the buttocks have been established as complications of the IS technique [1]. In this study, no patients were identified as having screw head prominence that either required revision surgery or resulted in pain, wound dehiscence, or poor cosmesis, which was inconsistent with previously reported results $[12,48]$. The difference in lower rate of wound complications associated with the IS technique may be attributed to the fact that we minimized the screw head profile when we deeply recessed pelvic screws into the PSIS specifically to avoid the issue of prominence. Our results suggest that IS fixation is an effective method for SPF. Ishida et al. [49] reported significantly higher rates of symptomatic implant prominence in an IS fixation group. In their study, the screw placement technique was not described and no mention was made of recessing the screw head into the ilium to minimize prominence. Rates of pseudarthrosis at L5-S1 and reoperation due to PJF were similar between their groups.

Limitations of our study include its retrospective design with small sample size and the asymmetry in the number of patients of two groups. However, this is a preliminary study conducted prior to further study in ASD population. Despite these limitations, we believe that the results of this study will be helpful clinically for many spine surgeons.

\section{Conclusions}

Compared with the S2AI technique, the IS technique usable larger cantilever force demonstrated more correction of lumbar lordosis, and possible increase in pelvic incidence. Further study is warranted to clarify the clinical impaction of these results. 


\section{Abbreviations}

ASD: Adult spinal deformity; IS: Iliac screw; S2AI: S2-alar-iliac screw; SPF: Spinopelvic fixation; SVA: Sagittal vertical axis; TK: Thoracic kyphosis; PT: Pelvic tilt; PI: Pelvic incidence; LL: Lumbar lordosis; ULL: Upper lumbar lordosis; LLL: Lower lumbar lordosis; PJK: Proximal junctional kyphosis; UIV: Upper instrumented vertebra; SIJ: Sacroiliac joint; ASA: American Society of Anesthesiologists; EBL: Estimated blood loss; VAS: Visual Analog Scale; ODI: Oswestry Disability Index

\section{Acknowledgements}

We would like to thank eWorldEditing (www.eworldediting.com) for the English language editing of this manuscript.

\section{Authors' contributions}

Conception and design: Yong-Chan Kim and Ki-Tack Kim. Acquisition of data: Qiang Luo, Min-Gyu Kim, and Sung-Min Kim. Analysis and interpretation of data: Qiang Luo, Yong-Chan Kim, and Joonghyun Ahn. Critical revision of the manuscript: Yong-Chan Kim, Ki-Tack Kim, and Kee-Yong Ha. Drafting the article: Qiang Luo. All authors have read and approved the final manuscript.

\section{Funding}

There is no funding source.

\section{Availability of data and materials}

The datasets used and/or analyzed during the current study are available from the corresponding author on reasonable request.

\section{Declarations}

\section{Ethics approval and consent to participate}

This study was approved by the Institutional Review Board (IRB\# 2020-10013) of the Kyung Hee University Hospital at Gangdong, Gangdong-gu, Seoul, Korea. The requirement for informed consent was waived by the IRB due to the retrospective nature of the study design. This study was performed in line with the principles of the Declaration of Helsinki.

\section{Consent for publication}

Not applicable.

\section{Competing interests}

The authors declare that they have no competing interests.

\section{Author details}

'Department of Orthopaedic Surgery, College of Medicine, Kyung Hee University Hospital at Gangdong, Kyung Hee University, 892 Dongnam-ro, Gangdong-gu, Seoul 05278, South Korea. ²Department of Orthopaedic Surgery, Graduate School of Medicine, Kyung Hee University,

Kyungheedae-ro, Dongdaemun-gu, Seoul, South Korea.

\section{Received: 4 May 2021 Accepted: 2 August 2021}

Published online: 10 August 2021

\section{References}

1. Kebaish KM. Sacropelvic fixation: techniques and complications. Spine. 2010; 35(25):2245-51. https://doi.org/10.1097/BRS.0b013e3181f5cfae.

2. Shen FH, Mason JR, Shimer AL, Arlet VM. Pelvic fixation for adult scoliosis. Europ Spine J. 2013;22(Suppl 2):S265-75.

3. Emami A, Deviren V, Berven S, Smith JA, Hu SS, Bradford DS. Outcome and complications of long fusions to the sacrum in adult spine deformity - Luque-Galveston, combined iliac and sacral screws, and sacral fixation. Spine. 2002;27(7):776-86. https://doi.org/10.1097/ 00007632-200204010-00017

4. Elder BD, Ishida W, Lo SFL, Holmes C, Goodwin CR, Kosztowski TA, et al. Use of S2-alar-iliac screws associated with less complications than iliac screws in adult Lumbosacropelvic fixation. Spine. 2017;42(3):E142-9. https://doi.org/1 0.1097/BRS.0000000000001722.

5. Guler UO, Cetin E, Yaman O, Pellise F, Casademut AV, Sabat MD, et al, Sacropelvic fixation in adult spinal deformity (ASD); a very high rate of mechanical failure. Europ Spine J. 2015:24(5):1085-91. https://doi.org/10.1 007/s00586-014-3615-1.
6. Kuklo TR, Bridwell KH, Lewis SJ, Baldus C, Blanke K, Iffrig TM, et al. Minimum 2-year analysis of sacropelvic fixation and L5-S1 fusion using S1 and iliac screws. Spine. 2001;26(18):1976-83. https://doi.org/10.1097/00007632-2001 09150-00007.

7. Chang TL, Sponseller PD, Kebaish KM, Fishman EK. Low profile pelvic fixation: anatomic parameters for sacral alar-iliac fixation versus traditional iliac fixation. Spine. 2009;34(5):436-40. https://doi.org/10.1097/BRS.0b013e31 8194128c.

8. Tsuchiya K, Bridwell KH, Kuklo TR, Lenke LG, Baldus C. Minimum 5-year analysis of L5-S1 fusion using sacropelvic fixation (bilateral S1 and iliac screws) for spinal deformity. Spine. 2006;31(3):303-8. https://doi.org/10.1 097/01.brs.0000197193.81296.f1.

9. Tsuchiya K, Bridwell KH, Kuklo TR, Lenke LG, Baldus C. Minimum 5-year analysis of L5-S1 fusion using Sacropelvic fixation (bilateral S1 and iliac screws) for spinal deformity. Spine (Phila Pa 1976). 2006;31(3):303-8.

10. Sponseller P. The S2 portal to the ilium. Semin Spine Surg. 2007;2:83-7.

11. Liu G, Hasan MY, Wong HK. Subcrestal iliac-screw: a technical note describing a free hand, in-line, low profile iliac screw insertion technique to avoid side-connector use and reduce implant complications. Spine. 2018; 43(2):E68-e74. https://doi.org/10.1097/BRS.0000000000002239.

12. Mazur MD, Ravindra VM, Schmidt MH, Brodke DS, Lawrence BD, RivaCambrin J, et al. Unplanned reoperation after lumbopelvic fixation with S-2 alar-iliac screws or iliac bolts. J Neurosurg-Spine. 2015;23(1):67-76. https:// doi.org/10.3171/2014.10.SPINE14541.

13. Shabtai $L$, Andras LM, Portman M, Harris LR, Choi PD, Tolo VT, et al. Sacral alar iliac (SAI) screws fail 75\% less frequently than iliac screws in neuromuscular scoliosis. J Pediatr Orthop. 2017;37(8):E470-5. https://doi. org/10.1097/BPO.0000000000000720.

14. Mayhew D, Mendonca $V$, Murthy BVS. A review of ASA physical status historical perspectives and modern developments. Anaesthesia. 2019;74(3): 373-9. https://doi.org/10.1111/anae.14569.

15. Zanoli G, Strömqvist B, Jönsson B. Visual analog scales for interpretation of back and leg pain intensity in patients operated for degenerative lumbar spine disorders. Spine. 2001;26(21):2375-80. https://doi.org/10.1097/ 00007632-200111010-00015.

16. Fairbank JC, Pynsent PB. The Oswestry disability index. Spine. 2000; 25(22):2940-52discussion 2952. https://doi.org/10.1097/00007632-2000111 50-00017

17. Nguyen JH, Buell TJ, Wang TR, Mullin JP, Mazur MD, Garces J, et al. Low rates of complications after spinopelvic fixation with iliac screws in 260 adult patients with a minimum 2-year follow-up. J Neurosurg-Spine. 2019; 30(5):635-43. https://doi.org/10.3171/2018.9.SPINE18239.

18. Cho W, Mason JR, Smith JS, Shimer AL, Wilson AS, Shaffrey Cl, et al. Failure of lumbopelvic fixation after long construct fusions in patients with adult spinal deformity: clinical and radiographic risk factors: clinical article. J Neurosurg Spine. 2013;19(4):445-53. https://doi.org/10.3171/2013.6. SPINE121129.

19. Moshirfar A, Rand FF, Sponseller PD, Parazin SJ, Khanna AJ, Kebaish KM, et al. Pelvic fixation in spine surgery. Historical overview, indications, biomechanical relevance, and current techniques. J Bone Joint Surg Am. 2005:87 Suppl 2:89-106.

20. Sponseller PD, Zimmerman RM, Ko PS, ter Gunne AFP, Mohamed AS, Chang $\mathrm{TL}$, et al. Low profile pelvic fixation with the sacral alar iliac technique in the pediatric population improves results at two-year minimum follow-up. Spine. 2010;35(20):1887-92. https://doi.org/10.1097/BRS.0b013e3181e03881.

21. O'Brien JR, Yu WD, Bhatnagar R, Sponseller P, Kebaish KM. An anatomic study of the S2 iliac technique for lumbopelvic screw placement. Spine. 2009:34(12):E439-42. https://doi.org/10.1097/BRS.0b013e3181a4e3e4.

22. Ishida W, Ramhmdani S, Casaos J, Perdomo-Pantoja A, Elder BD, Theodore $\mathrm{N}$, et al. Safety profile of Lumbosacropelvic fixation in patients aged 60 years or older comparison between S2-alar-iliac screws and conventional iliac screws. Clinical Spine Surg. 2019;32(4):E200-5. https://doi.org/10.1097/ BSD.0000000000000806.

23. Ray WZ, Ravindra VM, Schmidt MH, Dailey AT. Stereotactic navigation with the O-arm for placement of S-2 alar iliac screws in pelvic lumbar fixation. Neurosurg-Spine. 2013;18(5):490-5. https://doi.org/10.3171/2013.2.SPINE12 813.

24. Hoernschemeyer DG, Pashuck TD, Pfeiffer FM. Analysis of the s2 alar-iliac screw as compared with the traditional iliac screw: does it increase stability with sacroiliac fixation of the spine? Spine J. 2017;17(6):875-9. https://doi. org/10.1016/j.spinee.2017.02.001. 
25. Horton WC, Brown CW, Bridwell KH, Glassman SD, Suk SI, Cha CW. Is there an optimal patient stance for obtaining a lateral 36" radiograph? A critical comparison of three techniques. Spine. 2005;30(4):427-33. https://doi.org/1 0.1097/01.brs.0000153698.94091.f8.

26. Obeid I, Boniello A, Boissiere L, Bourghli A, Pointillart V, Gille O, et al. Cervical spine alignment following lumbar pedicle subtraction osteotomy for sagittal imbalance. Europ Spine J. 2015;24(6):1191-8. https://doi.org/10.1 007/s00586-014-3738-4.

27. Maruo K, Ha Y, Inoue S, Samuel S, Okada E, Hu SS, et al. Predictive factors for proximal junctional kyphosis in long fusions to the sacrum in adult spinal deformity. Spine. 2013;38(23):E1469-76. https://doi.org/10.1097/BRS. Ob013e3182a51d43.

28. Aichmair A, Alimi M, Hughes AP, Sama AA, Du JY, Härtl R, et al. Single-leve lateral lumbar interbody fusion for the treatment of adjacent segment disease: a retrospective two-center study. Spine. 2017:42(9):E515-e522. https://doi.org/10.1097/BRS.0000000000001871.

29. Marchi L, Abdala N, Oliveira L, Amaral R, Coutinho E, Pimenta L. Radiographic and clinical evaluation of cage subsidence after stand-alone lateral interbody fusion. J Neurosurg Spine. 2013:19(1):110-8. https://doi. org/10.3171/2013.4.SPINE12319.

30. Burkus JK, Transfeldt EE, Kitchel SH, Watkins RG, Balderston RA. Clinical and radiographic outcomes of anterior lumbar interbody fusion using recombinant human bone morphogenetic protein-2. Spine. 2002;27(21): 2396-408. https://doi.org/10.1097/00007632-200211010-00015.

31. Banno T, Hasegawa T, Yamato Y, Kobayashi S, Togawa D, Oe S, et al. Prevalence and risk factors of iliac screw loosening after adult spinal deformity surgery. Spine. 2017;42(17):E1024-30. https://doi.org/10.1097/BRS. 0000000000002047.

32. Sandén B, Olerud C, Petrén-Mallmin M, Johansson C, Larsson S. The significance of radiolucent zones surrounding pedicle screws. Definition of screw loosening in spinal instrumentation. J Bone Joint Surg (Br). 2004;86(3): 457-61

33. Kurosawa D, Murakami E, Ozawa H, Koga H, Isu T, Chiba Y, et al. A diagnostic scoring system for sacroiliac joint pain originating from the posterior ligament. Pain Med (Malden, Mass). 2017;18(2):228-38.

34. Camisa W, Bess S, Yi S, Washiya AS, Leasure JM, Burton DC, et al. Biomechanical demands on S2AI sacral and pelvic instrumentation in long fusion constructs with and without interbody supplementation. Spine J. 2014;14(11):S166. https://doi.org/10.1016/j.spinee.2014.08.400.

35. O'Brien JR, Matteini L, Yu WD, Kebaish KM. Feasibility of minimally invasive sacropelvic fixation: percutaneous S2 alar iliac fixation. Spine. 2010;35(4): 460-4. https://doi.org/10.1097/BRS.0b013e3181b95dca.

36. Le Huec JC, Demezon H, Aunoble S. Sagittal parameters of global cervical balance using EOS imaging: normative values from a prospective cohort of asymptomatic volunteers. Europ Spine J. 2015;24(1):63-71. https://doi.org/1 0.1007/s00586-014-3632-0.

37. Tseng CC, Liu Z, Bao HD, Li J, Zhao ZH, Hu ZS, et al. Long fusion to the pelvis with S2-alar-iliac screws can induce changes in pelvic incidence in adult spinal deformity patients: analysis of predictive factors in a retrospective cohort. Eur Spine J. 2019;28(1):138-45. https://doi.org/10.1007/ s00586-018-5738-2.

38. Place HM, Hayes AM, Huebner SB, Hayden AM, Israel H, Brechbuhler JL. Pelvic incidence: a fixed value or can you change it? Spine J. 2017;17(10): 1565-9. https://doi.org/10.1016/j.spinee.2017.06.037.

39. Bao H, Liabaud B, Varghese J, Lafage R, Diebo BG, Jalai $C$, et al. Lumbosacral stress and age may contribute to increased pelvic incidence: an analysis of 1625 adults. Europ Spine J. 2018;27(2):482-8.

40. Alderink GJ. The sacroiliac joint: review of anatomy, mechanics, and function. J Orthopaed Sports Phys Ther. 1991;13(2):71-84. https://doi.org/1 0.2519/jospt.1991.13.2.71

41. Sturesson B, Selvik G, Udén A. Movements of the sacroiliac joints. A roentgen stereophotogrammetric analysis. Spine. 1989;14(2):162-5. https:// doi.org/10.1097/00007632-198902000-00004

42. Tyrakowski M, Wojtera-Tyrakowska D, Siemionow K. Influence of pelvic rotation on pelvic incidence, pelvic tilt, and sacral slope. Spine. 2014;39(21): E1276-83. https://doi.org/10.1097/BRS.0000000000000532.

43. Cecchinato R, Redaelli A, Martini C, Morselli C, Villafañe JH, Lamartina C, et al. Long fusions to $\mathrm{S} 1$ with or without pelvic fixation can induce relevant acute variations in pelvic incidence: a retrospective cohort study of adult spine deformity surgery. Eur Spine J. 2017;26(Suppl 4):436-41. https://doi. org/10.1007/s00586-017-5154-z
44. Dreyfuss P, Dreyer SJ, Cole A, Mayo K. Sacroiliac joint pain. J Am Acad Orthopaed Surg. 2004;12(4):255-65. https://doi.org/10.5435/00124635-2004 07000-00006.

45. Ha KY, Lee JS, Kim KW. Degeneration of sacroiliac joint after instrumented lumbar or lumbosacral fusion: a prospective cohort study over five-year follow-up. Spine. 2008;33(11):1192-8. https://doi.org/10.1097/BRS.0b013e31 $8170 f d 35$.

46. Ivanov AA, Kiapour A, Ebraheim NA, Goel V. Lumbar fusion leads to increases in angular motion and stress across sacroiliac joint: a finite element study. Spine. 2009;34(5):E162-9. https://doi.org/10.1097/BRS.0b013 e3181978ea3.

47. Ishida W, Elder BD, Holmes C, Lo SFL, Goodwin CR, Kosztowski TA, et al. Comparison between S2-alar-iliac screw fixation and iliac screw fixation in adult deformity surgery: reoperation rates and spinopelvic parameters. Glob Spine J. 2017;7(7):672-80. https://doi.org/10.1177/2192568217700111.

48. Ilyas $\mathrm{H}$, Place $\mathrm{H}$, Puryear A. A comparison of early clinical and radiographic complications of iliac screw fixation versus S2 alar iliac (S2AI) fixation in the adult and pediatric populations. J Spinal Disord Tech. 2015;28(4):E199-205. https://doi.org/10.1097/BSD.0000000000000222.

49. Ishida W, Elder BD, Holmes C, Goodwin CR, Lo SFL, Kosztowski TA, et al. S2alar-iliac screws are associated with lower rate of symptomatic screw prominence than iliac screws: radiographic analysis of minimal distance from screw head to skin. World Neurosurg. 2016;93:253-60. https://doi.org/1 0.1016/j.wneu.2016.06.042

\section{Publisher's Note}

Springer Nature remains neutral with regard to jurisdictional claims in published maps and institutional affiliations.
Ready to submit your research? Choose BMC and benefit from:

- fast, convenient online submission

- thorough peer review by experienced researchers in your field

- rapid publication on acceptance

- support for research data, including large and complex data types

- gold Open Access which fosters wider collaboration and increased citations

- maximum visibility for your research: over $100 \mathrm{M}$ website views per year

At $\mathrm{BMC}$, research is always in progress.

Learn more biomedcentral.com/submissions 